\title{
ESTADO, DESENVOLVIMENTO \\ SUSTENTÁVEL E GOVERNANÇA NO \\ BRASIL: POLÍTICAS PÚBLICAS PARA \\ ENERGIA E ÁGUA Pós RIO-92
}

State, Sustainable Development and Governance in Brazil:

Public Policies for Energy and Water Post Rio-92 


\title{
RESUMO
}

Com o objetivo de compreender como se processou a incorporação do conceito de desenvolvimento sustentável às políticas públicas de gestão dos recursos naturais para a geração de energia, tomamos o uso da água como exemplo e problematizamos a questão a partir da discussão sobre o público e o privado na concepção de governança, entendida como ação do Estado na elaboração de políticas públicas. O espaço e o tempo da análise é o Brasil pós Conferência das Nações Unidas sobre Meio Ambiente e Desenvolvimento, a Rio 92, caracterizado pela reforma neoliberal iniciada com Fernando Collor de Mello e da retomada da criação de empresas estatais atuantes no uso dos recursos naturais em diálogo com o mercado durante os governos Luís Inácio Lula da Silva e Dilma Rousseff. A criação de uma estrutura institucional contemporânea aos princípios de desenvolvimento sustentável trouxe consigo a problemática da mudança na percepção quanto ao valor de uso e troca da água em que a questão do acesso frente a uma relação entre desiguais existente na gestão do Estado e entre iguais na sociedade civil participa das redefinições ocorridas com o advento do conceito difundido a partir de 1992. O conceito desenvolvimento sustentável se mostra indissociável da problemática do uso dos recursos naturais, cuja posição mais ao mercado ou mais ao Estado oscila entre as e dentro das ações estatais no que diz respeito a sua posição como agente econômico.

\section{PALAVRAS-CHAVE}

Brasil. Desenvolvimento sustentável. Políticas públicas.

\begin{abstract}
In order to understand how the concept of sustainable development was incorporated into public policies for the management of natural resources for energy generation, let's take water as an example and analyze the issue based on the discussion on public and private conception of governance as the action of the state in the elaboration of public policies. The space and time of the analysis is Brazil, after the United Nations Conference on Environment and Development, Rio 92, characterized by the neoliberal reform initiated by Fernando Collor de Mello and the resumption of the creation of state-owned companies dealing with the use of natural resources in Brazil, interacting with the market during Luís Inácio Lula da Silva and Dilma Rousseff's government. The creation of a contemporary institutional structure in accordance with the principles of sustainable development has brought with it the problem of a change in the perception of the value of water use and exchange, in which the issue of access, considering a relation between unequal, present in state management, and between equals, in Civil society participates in the redefinitions that occurred since 1992, when the concept was spread. The concept of sustainable development is inseparable from the problem of the use of natural resources, which position, either towards the market or the state, oscillates between and within state actions with regard to its position as an economic agent.
\end{abstract}

\section{KEYWORDS}

Brazil. Sustainable development. Public policy. 
$\mathbf{H}$ á inúmeras metodologias para se pensar a relação existente na tríade Estado, desenvolvimento sustentável e políticas públicas. Uma delas é o exame das relações entre política e sociedade a partir da triangulação do (1) surgimento da questão ambiental, (2) da organização institucional e (3) da ação do Estado e da mobilização da sociedade civil (MARTINEZ, 2016, p. 171). Considerando essa orientação teórico-metodológica, o objetivo deste artigo é refletir sobre o público e o privado na concepção de governança, nos atendo à ação do Estado na elaboração de políticas públicas. Tal reflexão será feita no contexto de incorporação do conceito desenvolvimento sustentável às leis e aos planos de curto e médio prazo para o uso de recursos naturais no setor de geração de energia, utilizando como exemplo a água.

No contexto da realização da Conferência das Nações Unidas sobre Meio Ambiente e Desenvolvimento, também conhecida como Rio 92, e na década subsequente, o Brasil viveu um processo de redemocratização e de reformas neoliberais do Estado ocorridas durante as gestões de Fernando Collor de Mello, Itamar Franco e Fernando Henrique Cardoso. Tal processo incluiu a criação de instrumentos legais de regulação do uso dos recursos naturais geradores de energia. O modelo de governança foi aberto ao mercado com as leis de desestatização e transferência de funções das empresas estatais para recém-criadas agências setoriais, como o ocorrido com a Agência Nacional de Águas (ANA), em 2000. Esse período foi seguido de um segundo momento, caracterizado pela criação de planos emergenciais de conservação de energia em decorrência da crise do apagão de 2000-2001, ainda no período $\mathrm{FHC}$. Um terceiro momento da atuação do Estado na estruturação da governança dos recursos naturais pós-Rio 92 correspondeu ao período Luís Inácio Lula da Silva e Dilma Rousseff. Houve, então, a retomada da criação de empresas estatais, como a Empresa de Pesquisa Energética (EPE), criada em 2004, e a elaboração e implantação dos programas e planos setoriais desenvolvidos pelas agências criadas no período $\mathrm{FHC}$ com foco na pesquisa e planificação, como o Plano Nacional de Recursos Hídricos (PNRH), finalizado em 2006. Esse segundo momento foi sucedido pela crise econômica de 2008 e exigiu um Estado regulador atuante. Questionamos: uma vez que o desenvolvimento sustentável foi definido como um compromisso do Estado e da sociedade civil, como o Estado organizou a governança dos recursos naturais em diálogo com o mercado?

Para desenvolver essa reflexão, nos apoiaremos no texto "A grande dicotomia: público e privado", de Norberto Bobbio, publicado no livro Estado, governo e sociedade: para uma teoria geral da política (1985), e no texto "Mercados, estado e oportunidade social", de Amartya Sen, publicado no livro Desenvolvimento como liberdade (1999). Para pensar o Brasil, trabalharemos o texto "Estado e meio ambiente no Brasil”, de Marcelo Bursztyn, publicado na coletânea por ele organizada e intitulada Para pensar o desenvolvimento sustentável (2003), e os capítulos "Os desafios da sustentabilidade e os bancos de desenvolvimento", escrito por Luciano Coutinho, e "Crises e oportunidades em tempos de mudanças", escrito por Ignacy Sachs, Carlos Lopes e Ladislau Dowbor, ambos publicados no livro Desenvolvimento, inovação e sustentabilidade: contribuições de Ignacy Sachs (2014), organizado por Carlos Lopes.

Primeiramente, apresentamos uma discussão das atribuições do Estado na implantação de políticas de desenvolvimento sustentável como indicado na Declaração do Rio de Janeiro e na Agenda 21, ambos documentos elaborados durante a Rio 92. Nela fazemos uma retomada da inserção do conceito desenvolvimento sustentável na política pública brasileira, considerando a reforma neoliberal do Estado na década 
de 1990 e a retomada da ação estatal na gestão dos recursos naturais em uma ação junto ao mercado na primeira década dos anos 2000. A segunda parte do texto propõe uma reflexão sobre como a questão do público e do privado está inserida nas políticas públicas de gestão de recursos naturais usando a questão da água como exemplo. Nessa parte recorremos ao artigo Política Nacional de Recursos Hídricos: governança da água e cidadania ambiental (2013), de Maria de Fátima S. Wolkmer e Nicole Freiberger Pimmel, e à discussão teórica sobre Estado, público e privado, a partir da leitura das obras já citadas de Norberto Bobbio e Amartya Sen. Concluímos com um balanço sobre como a triangulação sugerida por Martinez - surgimento da questão ambiental, organização institucional, ação do Estado e mobilização da sociedade civil - que dialoga com a trajetória da inserção do conceito desenvolvimento sustentável na legislação brasileira frente aos problemas teóricos apresentados sobre público, privado e Estado.

\section{REGULAMENTAÇÃO E POLÍTICAS DE MÉDIO PRAZO NO BRASILPÓS-RIO92:DESENVOLVIMENTOSUSTENTÁVEL, AÇÕES PROPOSTAS E REFORMA DO ESTADO}

O conceito desenvolvimento sustentável é definido no relatório Nosso Futuro Comum - também conhecido como Relatório Bruntland - como aquele capaz de garantir o atendimento às necessidades do presente sem comprometer a capacidade de as gerações futuras atenderem suas próprias necessidades (COMISSÃO MUNDIAL SOBRE MEIO AMBIENTE E DESENVOLVIMENTO, 1988, p. 9). Tal conceito chegou aos ouvidos dos brasileiros a partir da cobertura que a imprensa realizou da Conferência das Nações Unidas sobre Meio Ambiente e Desenvolvimento, popularmente conhecida pelos nomes de Rio 92, Eco 92 ou ainda Cúpula da Terra, realizada na cidade do Rio de Janeiro (RJ) entre os dias 3 e 14 de junho de 1992.

André Trigueiro, repórter da Rádio Jornal do Brasil durante a conferência, observa que as redações tiveram que contratar especialistas para a cobertura do evento internacional. Foi preciso se adaptar a um novo vocabulário, uma vez que cientistas de diversas áreas do conhecimento, bem como políticos e ativistas ambientais falavam sobre biodiversidade e efeito estufa, para citar alguns exemplos. Na ocasião, Washington Novaes, jornalista que atuou na cobertura do Fórum Global, realizado concomitantemente à conferência da Organização das Nações Unidas (ONU) no Aterro do Flamengo, pontua que na época a figura do ambientalista ganhou espaço na mídia e passou a ser protagonista, ditando pautas na imprensa (ECOS DA RIO-92, 2017).

Quando pensamos como a inserção do conceito desenvolvimento sustentável ocorreu no campo institucional, temos que recordar a elaboração do documento O desafio do desenvolvimento sustentável: relatório do brasil para a Conferência das Nações Unidas sobre Meio Ambiente e Desenvolvimento, finalizado em 1991. O documento foi elaborado pela Comissão Interministerial para a Preparação da Conferência das Nações Unidas sobre Meio Ambiente e Desenvolvimento (CIMA), composta por membros das secretarias executivas ligadas diretamente ao então presidente Fernando Collor de Mello, e presidida por Francisco Rezek, ministro das Relações Exteriores. A passagem de Rezek à frente do ministério foi marcada por uma 
política de não alinhamento às questões ambientais internacionais, que no mundo pós-Guerra Fria fizeram da Rio 92 um instrumento de promoção de uma perspectiva de aliança entre desenvolvimento econômico e conservação ambiental, ideal incluso no conceito desenvolvimento sustentável (PEGUIM, 2015, p. 14).

O Brasil já contava com políticas voltadas para o meio ambiente antes da realização da Rio 92: a Política Nacional de Meio Ambiente (PNMA), elaborada em 1981. Contudo, o relatório Desafio do desenvolvimento sustentável, além de marcar disputas por visões sobre a proteção e conservação da natureza e os possíveis usos de seus recursos, trouxe para o campo dos estudos de análise sobre a realidade brasileira encomendados pelo Estado nacional o conceito de desenvolvimento sustentável. Era algo que ainda não havia sido incorporado à Constituição de 1988. Paulo Henrique Martinez observa que: "os constituintes acolheram algumas disposições do Relatório Brundtland, de 1987, como a ideia de corresponsabilidade dos poderes públicos e da coletividade na defesa e na preservação do meio ambiente para as atuais e futuras gerações". No entanto, destaca que "uma ausência, porém, é notada no texto constitucional brasileiro, o Desenvolvimento Sustentável, tema central do debate mundial da década de 1980" (MARTINEZ, 2016, p. 179). Naquele contexto, a proposição do conceito refletiu a necessidade de reordenar o capitalismo por meio da adequação à escassez de recursos naturais, consequente da própria dinâmica predatória do capital, para manter sua expansão.

Quando pensamos a ação do Estado em meio ambiente pós-1992 temos então a herança de uma legislação ambiental elaborada em um período de ditadura militar, a PNMA, que precisa se adaptar a um período de internacionalização da demanda econômica por recursos naturais no contexto de regulações neoliberais e pressão internacional pela promoção do desenvolvimento sustentável. Considerando essa conjuntura, observamos que as políticas públicas sobre meio ambiente no Brasil e a organização das formas de governo a respeito do uso dos recursos naturais também passaram por uma reordenação.

RefletindosobreatríadeEstado, desenvolvimento sustentávele políticas públicas, podemos questionar: o Estado viabilizou um desenvolvimento economicamente viável, ecologicamente suportável e socialmente equitativo? Essa questão é elaborada a partir da reflexão do economista Ignacy Sachs e de sua trajetória na elaboração do conceito desenvolvimento sustentável. Economista formado no Brasil e com doutorado na Índia, fundador do Centro de Pesquisas sobre o Brasil Contemporâneo na École des Hautes Études em Sciences Sociales (EHESS), Sachs (apud PEGUIM, 2014, p. 516) observa que

a questão sobre qual estilo de desenvolvimento optar residiria em suas finalidades (que) e instrumentos (como). Em busca de tal resposta, interessaria explicitar os estilos de desenvolvimento ecologicamente prudentes e socialmente justos de cada comunidade em busca do que denomina dupla função ética do desenvolvimento: as finalidades sociais e cuidados com as gerações vindouras.

Vamos iniciar a problematização da questão elencando algumas especificidades da ação do Estado documentadas na Declaração do Rio de Janeiro. 
Assinado durante a Rio 92, é um documento formado por 27 princípios básicos que deveriam ser incorporados pelos Estados signatários nas suas políticas de desenvolvimento. Em conformidade com a Carta das Nações Unidas e com os Princípios de Direito Internacional, a declaração assegurava ao Estado "o direito soberano de explorar seus próprios recursos segundo suas próprias políticas de meio ambiente e desenvolvimento" (Princípio 2). A ele também caberia agir de forma a eliminar padrões insustentáveis de produção e consumo, incluindo a promoção de políticas demográficas (Princípio 8). A capacitação endógena para o desenvolvimento sustentável foi posta como tarefa dos Estados, que deveriam cooperar com o aprimoramento da compreensão científica, o intercâmbio de conhecimento, o desenvolvimento, a adaptação, a difusão e a transferência de tecnologias (Princípio 9) (DECLARAÇÃO DO RIO, 1992).

A erradicação da pobreza figurou como um conceito-chave na atuação do Estado perante a comunidade internacional e a sociedade civil (Princípio 5). Ao Estado também caberia promover a participação pública dos processos de decisão e o acesso aos processos judiciais e administrativos sobre compensação e reparação de danos (Princípio 10). O bom cumprimento do Princípio 10 estava vinculado a uma legislação ambiental eficaz (Princípio 11) que responsabilizasse por poluição e danos ambientais e indenizasse suas vítimas (Princípio 13). A ação do Estado para a promoção do desenvolvimento sustentável também incluía o reconhecimento da participação das mulheres na promoção do desenvolvimento sustentável (Princípio 20), o protagonismo das populações indígenas na gestão do território (Princípio 22) e a proteção do meio ambiente e de recursos naturais dos povos submetidos à opressão, dominação e ocupação (Princípio 23), com a internalização dos custos ambientais (Princípio 17) (DECLARAÇÃO DO RIO, 1992).

Além da Declaração do Rio de Janeiro, outro documento foi base para a institucionalização do desenvolvimento sustentável pós-Rio 92: a Agenda 21. Foi elaborado como um programa de ação composto por quarenta capítulos correspondentes a três faces do processo de implantação do desenvolvimento sustentável: (1) dimensões sociais e econômicas, (2) a conservação e o gerenciamento de recursos para o desenvolvimento e (3) os meios de implementação desse programa. O êxito e a responsabilidade de sua execução caberiam aos governos que teriam de elaborar estratégias, planos e políticas, e fomentar o processo de implantação da agenda, podendo recorrer à cooperação internacional como complemento aos esforços nacionais (ONU, 2001).

No Brasil, o período dos governos Fernando Collor (1990-1992), Itamar Franco (1992-1995) e Fernando Henrique Cardoso (1995-2003) correspondeu à elaboração da Agenda 21 Brasileira. O documento, elaborado em duas fases, é composto pela Agenda 21: ações prioritárias e Agenda 21: resultado da consulta nacional, e foi concluído em 2002, ano da realização da Cúpula Mundial sobre Desenvolvimento Sustentável, realizada em Joanesburgo, África do Sul. Seu objetivo foi elaborar metas nacionais a partir do programa global de ação Agenda 21 assinado na Rio-92.

Quando falamos de recursos naturais, energia, água e desenvolvimento sustentável, é preciso recordar outra característica do período entre Collor e FHC: a privatização do setor elétrico e a flexibilização do monopólio estatal do petróleo. Esse processo incluiu a criação de três agências reguladoras setoriais: a Agência Nacional de Energia Elétrica (ANEEL), em 1996; a Agência Nacional do Petróleo, Gás Natural e Biocombustíveis (ANP), em 1997; e a Agência Nacional de Águas (ANA), em 2000. 
Também incluiu a elaboração de leis de regulamentação do uso dos recursos hídricos com a Política Nacional de Recursos Hídricos, em 1997, conhecida como Lei de Águas. Por meio da Lei de Águas foram criados outros instrumentos administrativos, tais como o Sistema Nacional de Recursos Hídricos (SNRH) e o Conselho Nacional de Recursos Hídricos (CNRH).

Marcel Bursztyn (1993, p. 85) observou que "Até mesmo os mais radicais expoentes do pensamento neoliberal viriam a admitir que nesse terreno caberia ao Estado o papel de definição das regras do jogo econômico e de assegurar o seu cumprimento". Podemos observar a existência de um processo de inclusão do conceito desenvolvimento sustentáve/ na legislação brasileira a partir de leis que incorporaram a discussão sobre uma gestão dos recursos pautada em sua métrica - ou seja, na aferição da quantidade e na disponibilidade de seu uso, principal função das agências setoriais criadas pelo Estado. Trata-se de uma percepção técnica, porém prevista nas metas de desenvolvimento sustentável.

Se durante o período FHC houve a criação de políticas nacionais e agências de regulação, no período Luiz Inácio Lula da Silva (2003-2011), com Marina Silva como ministra do Meio Ambiente (2003-2008) e Dilma Rousseff e Silas Rondeau na liderança do Ministério de Minas e Energia (2003-2005/2005-2007), observamos a criação de programas e planos de curto e médio prazo como o Programa Nacional de Produção e Uso do Biodiesel (PNPB) voltados para a energia gerada a partir de biomassa e biocombustíveis, em 2004, o Plano Decenal de Expansão da Energia Elétrica (PDEE 2015) e o PNRH, ambos em 2006, com ação na expansão da geração e transmissão de energia hidroelétrica. A EPE, criada em 2004, foi responsável pela elaboração do PDEE (2006/2015), formulado como previsto nas leis n. 10.847 e 10.848, de 15 de março de 2004. A expansão programada pelo PDEE para o decênio 2006/2015 incluiu a entrada em operação das hidrelétricas de Jirau e Santo Antônio, ambas no rio Madeira, e de Belo Monte, no Xingu (BRASIL, 2006).

As ações e projeções apresentadas no PDEE tinham qualidade, eficiência e eficácia como ideias-chave da proposta para o setor elétrico. Essas ideias foram direcionadas principalmente para o Sistema Interligado Nacional (SIN). O SIN foi criado em 1998 pela Lei n. 9.648/98 como parte do pacote de reestruturação da Eletrobras, e foi planejado como um sistema hidrotérmico. Composto por uma rede de usinas de geração de fontes hídricas e térmicas, como biomassa, o SIN conta com uma ampla rede de transmissão interligando as regiões Sul, Sudeste/Centro-Oeste, Nordeste e parte da região Norte.

Para compreender a criação do SIN, devemos nos recordar de que o consumo de eletricidade no Brasil na última década do século XX aumentou em razão da eletrificação crescente do país e da instalação de indústrias eletrointensivas (GOLDEMBERG; LUCON, 2007, p. 10). A busca por matéria-prima e mão de obra baratas nos países em desenvolvimento, como o Brasil, e a articulação de um sistema econômico cada vez mais interligado, exigente em infraestrutura, transporte comunicações e fontes de energia, somada ao aumento populacional fizeram com que, em fins dos anos 1990, o país passasse por um colapso físico do sistema elétrico em consequência da redução da capacidade dos reservatórios das hidrelétricas, principalmente nas regiões Norte e Sudeste - a chamada crise do apagão. Essa crise levou ao racionamento de energia e demandou políticas de conservação (LEITE, 2014).

Esse cenário de crise está relacionado a uma política estatal internacional, no âmbito da América Latina, de disponibilidade de recursos e menores restrições 
ambientais com o objetivo de atrair a transferência de indústrias (PEGUIM, 2017, p. 5). O afluxo de empresas para os países em desenvolvimento gerava uma maior demanda para os sistemas de geração de energia, aumentando a pressão sobre os estados a fim de que alcançassem a segurança energética. Consequentemente, houve maior pressão sobre os recursos naturais geradores de energia (ALBAVERA, 1995). Esse processo de internacionalização e privatizações dos anos 1990, com maior abertura para as empresas detentoras das mudanças tecnológicas, confronta-se com a emergência de um questionamento sobre a vida útil e da sustentabilidade ambiental dos processos de exploração dos recursos naturais presente na realidade brasileira. Isso se dá a partir da inserção do tema desenvolvimento sustentável como pauta cotidiana na mídia nacional, no mercado econômico e nas relações exteriores.

Nesse cenário, a crise econômica de 2008 emerge como fator para uma reflexão sobre a gestão dos recursos naturais brasileiros. No período pós-2008, verificou-se que "a dinâmica do crescimento da renda mundial passou a ter uma participação muito importante dos países em desenvolvimento, com destaque para os BRICS (grupo de países economicamente emergentes formado por Brasil, Rússia, Índia, China e África do Sul)" (COUTINHO, 2014, p. 23). A crise evidenciou as questões sociais e ambientais, colocando no centro da discussão sobre desenvolvimento a distribuição de renda, a segurança alimentar, a saúde, o saneamento, a preservação de recursos hídricos, o combate ao desmatamento e o uso sustentável de florestas.

Sobre a crise de 2008, Ignacy Sachs, Carlos Lopes e Ladislau Dowbor (2014, p. 54) em "Crises e oportunidades em tempo de mudança", apresentam uma crítica ao Estado neoliberal adotado como política desde os anos 1990, caracterizado, segundo os autores, por "forças caóticas de mercado, com um pouco de regulação pública e com organizações da sociedade civil tapando os buracos ou consertando as falhas mais dramáticas". Ou seja, a regulação pública exercida pelo Estado ao lado do mercado como agente econômico apresentava falhas expressas na crise então vivenciada.

Quando pensamos a relação da crise com as metas de desenvolvimento sustentável, como direito à exploração de recursos, erradicação da produção e consumo insustentáveis e proteção ao meio ambiente, colocando o mercado no centro, precisamos entender o peso do papel do mercado no conceito desenvolvimento sustentável. No relatório Nosso futuro comum, a solução de uso e manutenção dos recursos naturais e das políticas de desenvolvimento está vinculada à regulação do mercado, de modo que os caminhos do desenvolvimento não passariam pelo crivo do planejador e das comunidades, mas sim por multinacionais e organismos internacionais (PEGUIM, 2015, p. 52).

Quando nos deparamos com as ações propostas na Declaração do Rio de Janeiro e na Agenda 21, podemos ver na trajetória da institucionalização do conceito desenvolvimento sustentável no Brasil uma demanda internacional pela ação do Estado. Essa demanda deveria criar um espaço para implantar políticas propostas pela ONU por meio do diálogo com a sociedade civil, formada pela população com direito às metas que cabiam ao Estado ou com direito ao ressarcimento do ônus por ele causado. A governança dos recursos naturais no Brasil passou por um processo de regulação e elaboração de planos de médio prazo no período analisado. Tal processo dialoga com a demanda da política ambiental global, mas também responde a uma demanda econômica interna de adequação a um mercado de recursos. A regulação desse mercado se dá por meio de um imperativo de desenvolvimento econômico 
imbuído de valores positivos de independência e autorrealização traduzidos em aumento da produtividade e na segurança energética do Brasil.

Uma vez que os recursos naturais deveriam corresponder a esses imperativos e ao mesmo tempo ser preservados para as futuras gerações, trazer para a discussão a questão do mercado, como colocada no relatório Nosso futuro comum, é necessário para problematizarmos a questão do público e do privado na governança dos recursos naturais. Essa dupla coloca para nós uma questão central quando falamos das relações entre ser humano e mundo natural: o acesso. Propomos uma reflexão sobre essa problemática usando como exemplo a água.

\section{RECURSOS NATURAIS, ESTADO E POLÍTICAS PÚBLICAS ENTRE O PÚBLICO E O PRIVADO: A ÁGUA COMO EXEMPLO}

Recursos naturais é uma expressão que no início do século XXI está associada no imaginário coletivo a uma visão monetarizada da natureza. A Agenda 21 foi elaborada dentro desse referencial teórico e contribuiu para a percepção da água como recurso ao defini-la como bem econômico. Segundo a Agenda 21 (ONU, 2001, p. 33), "O manejo integrado dos recursos hídricos baseia-se na percepção da água como parte integrante do ecossistema, um recurso natural e bem econômico social cujas quantidade e qualidade determinam a natureza da sua utilização".

Para a gestão da água, os Estados nacionais que ratificaram em 1992 a Agenda 21, entre eles o Brasil, deveriam criar e executar estruturas institucionais, instrumentos jurídicos e programas de uso eficiente de água. Os recursos hídricos deveriam ser geridos de forma compartilhada com o fortalecimento de iniciativas locais vinculadas à cooperação entre Estados (RIBEIRO, 2001, p. 86-87). Para 2005, os Estados deveriam ter atingido as metas subsetoriais propostas pela Agenda 21 segundo Resolução n. 44/2228 da Assembleia Geral da ONU.

No Brasil, dentro do limite estipulado pela ONU, houve a elaboração da Política Nacional de Recursos Hídricos, em 1997, a criação da Agência Nacional de Águas (ANA) em 2000, e a proposição do PNRH, em 2006. Estruturas institucionais, instrumentos jurídicos e programas de uso da água viabilizados dentro de um quadro teórico de concepção da água como recurso natural, de mercado como agente econômico e do Estado como criador das agências reguladoras.

Maria de Fátima S. Wolkmer e Nicole Freiberger Pimmel (2013, p. 173) argumentam que o reconhecimento do valor econômico mudou a percepção da água de recurso abundante para recurso finito:

Ao reconhecer a água como um bem escasso, dotado de valor econômico, transita-se da percepção d'água como bem em abundância na natureza para a percepção da sua finitude. Essa mudança produz uma série de consequências, expressas no fundamento da Lei n. 9.433/97, qual seja a água passa a ser conceituada como um recurso limitado, dotado de valor econômico.

Para compreendermos a percepção da água como mercadoria, precisamos compreender a conexão entre escassez e acesso. Rodrigues (2019, p. 72) observa que "É preciso ressaltar que a escassez nem sempre significa ausência de Água, [pois] 
há situações, principalmente nos países pobres, em que existe riqueza hídrica, mas há pobreza no acesso". O acesso está diretamente vinculado aos marcos institucionais de cada país e da correlação de forças entre os atores legais do sistema de gestão da água.

A diversidade e as divergências entre as corporações e os movimentos socioambientais elevam a governança hídrica como um grande desafio para a sociedade. Isso porque as condições, quantidade e qualidade do acesso humano à Água dependem do modelo de governança hídrica adotado (RODRIGUES, 2019, p. 65).

Wolkmer e Pimmel (2013, p. 172), sobre a Política Nacional de Recursos Hídricos, observam que:

O domínio público da água foi ratificado pela Lei n. 9.433/97 [...] no entanto, isso não transforma o Poder Público Federal e Estadual em proprietário da água, mas o torna gestor desse bem, no interesse de todos. O ente público não é proprietário, senão no sentido formal (tem poder de autotutela do bem), na substância é um simples gestor do bem de uso coletivo. ${ }^{1}$

Norberto Bobbio (2007, p. 14) faz uma colocação que pode nos servir de base para pensar o tamanho das esferas do público e do privado em políticas de desenvolvimento sustentável como as da governança da água:

Um dos lugares-comuns do secular debate sobre a relação entre a esfera do público e a do privado é que, aumentando a esfera do público, diminui a do privado, e aumentando a esfera do privado diminui a do público; uma constatação que é geralmente acompanhada e complicada por juízos de valor contrapostos.

Nessa direção, Amartya Sen, ao falar sobre a eficiência dos mercados, inclui na sua argumentação a tese da otimalidade de Pareto. Descreve-a como "uma situação na qual a utilidade (ou bem-estar) de qualquer pessoa não pode ser aumentada sem reduzir a utilidade (ou bem-estar) de alguma outra" (SEN, 2010, p. 157). Público e privado, em direito, acabam por traduzir a forma como relações sociais se ordenam, estabelecendo dois tipos de relações: entre iguais e entre desiguais (BOBBIO, 2007, p. 15).

Vamos pensar as definições de público e privado frente ao Estado, segundo Bobbio (2007, p. 15):

O Estado, ou qualquer outra sociedade organizada onde existe uma esfera pública, não importa se total ou parcial, é caracterizado por relações de subordinação entre governantes e governados, ou melhor, entre detentores do poder de comando e destinatários do dever de obediência, que são relações entre desiguais [...].

${ }^{1}$ Cf. Henkes (2003). 
[...] a sociedade natural tal como descrita pelos jusnaturalistas, ou a sociedade de mercado na idealização dos economistas clássicos, na medida em que são elevadas a modelo de uma esfera privada contraposta à esfera pública, são caracterizadas por relações entre iguais ou de coordenação.

Os dois trechos oferecem suporte para pensarmos sobre Estado e sociedade civil uma vez que esta última é concebida como agente do desenvolvimento sustentável junto ao Estado ao se organizar como ator político e econômico atuante no mercado. Das situações elencadas por Bobbio, uma se relaciona com a questão ambiental: a sociedade global e os grupos menores. O autor conceitua sociedade civil a partir de Hegel e Marx, definindo-a como um sistema de necessidades incluso na compreensão jusnaturalista de um Estado de natureza vinculado a uma esfera econômica de relações entre iguais (BOBBIO, 2007, p. 15, 17).

Sobre a relação Estado e mercado, os níveis de relações entre iguais e desiguais, Amartya Sen (2010, p. 168) argumenta a favor da "necessidade de uma abordagem múltipla", ou seja, de uma ação com Estado e mercado:

As razões para adotar uma abordagem múltipla do desenvolvimento tornaram-se mais claras em anos recentes, em parte como resultado das dificuldades enfrentadas e dos êxitos obtidos por diferentes países ao longo das últimas décadas. Essas questões relacionam-se estreitamente à necessidade de equilibrar o papel do governo - e de outras instituições políticas e sociais - com o funcionamento dos mercados.

Mas como pensar essa ação do mercado sobre bens públicos? Podem ser considerados bem públicos aqueles "que as pessoas consomem juntas, e não separadamente. Isso se aplica em particular a áreas como preservação ambiental, além das de epidemiologia e serviços públicos de saúde" (SEN, 2010, p. 171). Para Amartya Sen (2010, p. 190):

Não se pode duvidar das contribuições do mecanismo de mercado para a eficiência, e os resultados econômicos tradicionais, nos quais a eficiência é julgada segundo a prosperidade, a opulência ou a utilidade, podem ser estendidos também para a eficiência no que se refere às liberdades individuais.

Aqui é importante esclarecer o conceito de liberdades individuais substantivas para Amartya Sen. Para o economista indiano, ganhador do Prêmio Nobel da Paz com o estudo Desenvolvimento como liberdade, liberdades são meios para o desenvolvimento, não apenas o seu fim. Envolvem tanto os processos que permitem a liberdade de ações e decisões como as oportunidades reais que as pessoas têm, dadas as suas circunstâncias pessoais e sociais (SEN, 2010, p. 32-33):

Assim, atenta-se particularmente para a expansão das 'capacidades' [capabilities] das pessoas levar o tipo de vida que elas valorizam - e com razão. Essas capacidades podem ser aumentadas pela política pública, mas também, por outro lado, a 
direção da política pública pode ser influenciada pelo uso efetivo das capacidades participativas do povo.

A posição de Ignacy Sachs, Carlos Lopes e Ladislau Dowbor diverge da de Amartya Sen quanto ao papel do mercado como promotor de capacidades. O foco dos autores é o resgate da capacidade de gestão pública, com um Estado que atuasse como "instrumento de coordenação de esforços sociais" e "como regulador do conjunto dos esforços da sociedade" (SACHS; LOPES; DOWBOR, 2014, p. 37). Assim, o Estado atuaria como agente social de uma governança participativa e distribuidor de Justiça, capacidades e conhecimento. Diante de um mercado cada vez mais neoliberal, observa-se que era necessária a "democratização das decisões sobre como são utilizados os recursos econômicos do planeta", orçamentos públicos participativos, uso dos recursos com visão sistêmica e com prioridade à redução de desastres ambientais e sociais (SACHS; LOPES; DOWBOR, 2014, p. 50).

Na direção de uma visão sistêmica, Luciano Coutinho (2014, p. 20-21), ao falar sobre o Banco Nacional do Desenvolvimento Econômico e Social (BNDES), entre 2005 e 2012, traz para a discussão da ação do Estado em políticas de desenvolvimento a metáfora dos cinco dedos da mão invisível do desenvolvimento sustentável, elaborada por Ignacy Sachs: (1) renovação do contrato social com redução do tempo de trabalho; (2) segurança alimentar e produção sustentável de alimentos; (3) segurança energética com maior intensidade em projetos e uso sobre fontes renováveis; (4) planejamento participativo de longo prazo entre governos, empresas, trabalhadores e sociedade civil organizada; e (5) cooperação internacional com ênfase nos países do sul e na direção do desenvolvimento socialmente includente e socialmente sustentável.

\section{CONSIDERAÇÕES FINAIS}

Vimos que na Declaração do Rio de Janeiro havia um conjunto de princípios que, para serem concretizados, necessitavam da ação do Estado na elaboração de legislação ambiental nacional e marcos institucionais regulatórios, na valorização da ciência e da tecnologia e na criação de mecanismos de participação popular. Também vimos que o relatório Nosso futuro comum, que antecedeu a declaração em termos de uma cronologia da elaboração da dinâmica do conceito desenvolvimento sustentável, incluiu o mercado como um agente promotor daquela perspectiva de desenvolvimento, implicando uma reordenação nas políticas públicas de gestão dos recursos naturais.

No Brasil, o período pós-1992 foi de transição das políticas de uso desses recursos, antes gerenciados pelas empresas estatais, para agências responsáveis por regular a privatização e uso, como a ANEEL, ANP e ANA, e a inserção de uma empresa estatal, a EPE, no campo da mensuração dos recursos disponíveis no território brasileiro, além de estudos que embasaram a elaboração de planos de curto e médio prazo para o setor energético. A elaboração das políticas de águas e energia, bem como a elaboração dos planos setoriais, como o PDEE 2006/2015, se enquadraram no compromisso estabelecido na Agenda 21 com a execução de estruturas institucionais e instrumentos jurídicos até 2005. Mas essa única face do desenvolvimento sustentável não suporta a efetivação do conceito na prática das políticas públicas para o uso da água, ficando ausentes ações concretas de participação popular. 
Agovernança sobre a água, nosso exemplo neste texto, incluiu alguns conceitos que nos remetem à discussão sobre público e privado. Na Agenda 21, a água foi definida como um recurso natural e bem econômico social. Na Política Nacional de Recursos Hídricos, o poder público federal e estadual foi considerado gestor desse bem. Água como bem econômico remete à ideia de oferta e procura, e como Wolkmer e Pimmel (2013) colocaram, à ideia de escassez.

Se o bem econômico social ou bem de uso coletivo é escasso, o acesso é incerto. O Estado é gestor, mas pode outorgar essa responsabilidade ao mercado. Se a gestão é privada, o acesso é precificado, e a relação de desequilíbrio estabelecida a partir da otimalidade de Pareto se coloca como um impasse na elaboração de políticas públicas. Ou seja, a maior participação do público na gestão da água leva à redução da participação dos setores privados. Por sua vez, a maior participação do mercado por meio das privatizações pode reduzir a ação de uma governança pública e a participação dos usuários múltiplos na governança sustentável desse bem, como colocado no Princípio 10 da Declaração do Rio de Janeiro.

Acompanhando Norberto Bobbio (2007), Amartya Sen (2010), Luciano Coutinho (2014), Ignacy Sachs, Carlos Lopes e Ladislau Dowbor (2014), podemos observar que o raciocínio elaborado por esses autores, atuantes na esfera da gestão pública, nos indica que o conceito desenvolvimento sustentável é indissociável da problemática do uso dos recursos naturais. Além disso, traz consigo a visualização de um "cabo de guerra" entre modelos de governança, hora mais ao mercado hora mais ao Estado, oscilando entre as e dentro das ações estatais, no período 1992 e 2012, no que diz respeito à regulação das questões ambientais.

\section{REFERÊNCIAS}

ALBAVERA, Fernando Sanchéz. El actual debate sobre los recursos naturales. Revista CEPAL. Santiago, n. 56, p. 125-135, 1995.

BOBBIO, Norberto. A grande dicotomia: público/privado. In: BOBBIO, Norberto. Estado, governo e sociedade: para uma teoria geral da política. São Paulo: Paz e Terra, 2007. p. 13-27.

BRASIL. Ministério de Minas e Energia. Plano Decenal de Expansão de Energia Elétrica: 2006-2015. Brasília: MME; EPE, 2006.

BRASIL. Ministério do Meio Ambiente. Secretaria de Recursos Hídricos. Plano Nacional de Recursos Hídricos. Caderno Setorial Geração de Energia Elétrica. Brasília: MMA, 2006.

BURSZTIN, Marcel. Estado e meio ambiente no Brasil. In: BURSZTIN, Marcel. Para pensar o desenvolvimento sustentável. São Paulo: Brasiliense. 1993. p. 83-114.

COUTINHO, Luciano. Os desafios da sustentabilidade e os bancos de desenvolvimento: lições de Ignacy Sachs. In: LOPES, Carlos et al. Desenvolvimento, inovação e sustentabilidade: contribuições de Ignacy Sachs. Rio de Janeiro:

Garamond, 2014. p. 19-36. 
DECLARAÇÃO DO RIO sobre Desenvolvimento e Meio Ambiente. Estudos Avançados, Rio de Janeiro, v. 6, n. 15, p. 153-159, 1992.

ECOS DA RIO-92: 25 anos depois. Apresentação disponível em: https:// museudoamanha.org.br/pt-br/content/ecos-da-rio-92-25-anos-depois. Programação disponível em: https://museudoamanha.org.br/sites/default/files/Programação\%20 Ecos\%20da\%20Rio\%2092_7.pdf. Acesso em: 10 set. 2019. Informações vide anotações de pesquisa de campo realizada pela pesquisadora.

FUNDAÇÃO GETÚLIO VARGAS. Centro de Pesquisa e Documentação de História Contemporânea do Brasil. José Lutzemberger. Disponível em: http://www.fgv.br/CPDOC/BUSCA/dicionarios/verbete-biografico/jose-antoniolutzenberger. Acesso em: 13 mar. 2019.

GOLDEMBERG, José; LUCON, Oswaldo. Energia e meio ambiente no Brasil. Estudos Avançados, São Paulo, v. 21, n. 59, p. 7-20, 2007.

HENKES, S. L. Política Nacional de Recursos Hídricos e Sistema Nacional de Gerenciamento de Recursos Hídricos. Jus Navigandi, Teresina, v. 8, n. 64, 2003. Disponível em: http://jus.uol.com. br/revista/texto/3970. Acesso em: 27 mar. 2011.

LEITE, Antonio Dias. A energia do Brasil. 3. ed. rev. e atual. Rio de Janeiro: Lexikon Editorial, 2014.

MARTINEZ, Paulo Henrique. Estado, políticas públicas e meio ambiente no Brasil. In: ABRÃO, Janete Silveira (coord.). Brasil: interpretações e perspectivas. São Paulo: Marcial Pons; Universidad de Alcala; Instituto Universitário de Investigación en Estudios Latinoamericanos, 2016. p. 172-195.

ONU - ORGANIZAÇÃO DAS NAÇÕES UNIDAS. Comissão mundial sobre meio ambiente e desenvolvimento. Nosso futuro comum. Rio de Janeiro: FGV, 1988.

ONU - ORGANIZAÇÃO DAS NAÇÕES UNIDAS. Conferência das Nações Unidas sobre meio ambiente e desenvolvimento (1992: Rio de Janeiro). Agenda 21. 3. ed. Brasília: Senado Federal; Subsecretaria de Edições Técnicas, 2001.

PEGUIM, Cássia Natanie. Desenvolvimento sustentável e recursos naturais: o Brasil (1992 - 2002). In: SIMPÓSIO NACIONAL DE HISTÓRIA - CONTRA OS PRECONCEITOS: HISTÓRIA E DEMOCRACIA, 2017, Brasília. Anais [...] Brasília, ANPUH, 2017. p. 1-8.

PEGUIM, Cássia Natanie. Ignacy Sachs em busca do ecodesenvolvimento. In: XXXI SEMANA DE HISTÓRIA: 'PALAVRA E DESTINO COMUM', 2014, Assis. Anais [...] Assis: FCL/Assis, 2014. p. 512-523.

PEGUIM, Cássia Natanie. Meio ambiente e desenvolvimento: a construção do debate ambiental em O Correio da UNESCO (1972-1992). Orientador: Paulo Henrique Martinez. 2015. 154f. Dissertação (mestrado) - Universidade Estadual 
Paulista Júlio de Mesquita Filho, Faculdade de Ciências e Letras de Assis, 2015. Disponível em: http://hdl.handle.net/11449/132042.

REMOND, René (org.). Por uma história política. Trad. Dora Rocha. 2. ed. Rio de Janeiro: FGV, 2003.

RODRIGUES, Arlindo. Gestão hídrica: governança dos bens comuns. São Paulo: Origem, 2019.

RIBEIRO, Wagner C. A ordem ambiental internacional. São Paulo: Contexto, 2001.

SACHS, Ignacy; LOPES, Carlos; DOWBOR, Ladislau. Crises e oportunidades em tempos de mudança. In: LOPES, Carlos et al. Desenvolvimento, inovação e sustentabilidade: contribuições de Ignacy Sachs. Rio de Janeiro: Garamond, 2014. p. 37-80.

SEN, Amartya. Desenvolvimento como liberdade. Trad. Laura Teixeira Mota. São Paulo: Companhia das Letras, 2010.

WOLKMER, Maria de Fátima S.; PIMMEL, Nicole Freiberger. Política Nacional De Recursos Hídricos: governança da água e cidadania ambiental. Sequência, Florianópolis, n. 67, p. 165-198, 2013. Disponível em: http://dx.doi.org/10.5007/21777055.2013v34n67p165.

\section{NOTAS}

\section{AUTORIA}

Cássia Natanie Peguim: Mestre. Doutoranda, Universidade Estadual Paulista Júlio de Mesquita Filho, Faculdade de Ciências e Letras, Departamento de História, Assis, SP, Brasil.

\section{ENDEREÇO PARA CORRESPONDÊNCIA}

Av. Dom Antonio, 2100, Parque Universitário, 9806-900, Assis, SP, Brasil.

\section{ORIGEM DO ARTIGO}

Extraído do projeto de pesquisa "O Brasil e o desenvolvimento sustentável: Estado e Recursos Naturais (1992-2012)", apresentado ao Programa de Pós-graduação História e Sociedade da Universidade Estadual Paulista, em 2016.

\section{AGRADECIMENTOS}

Agradecimentos devidos ao professor orientador Paulo Henrique Martinez.

\section{FINANCIAMENTO}

Este artigo foi financiado com bolsa de doutorado da Fundação de Apoio à Pesquisa do Estado de São Paulo (FAPESP), Processo 2016/23033-0.

\section{LICENÇA DE USO}

Este artigo está licenciado sob a Licença Creative Commons CC-BY. Com essa licença você pode compartilhar, adaptar e criar para qualquer fim, desde que atribua a autoria da obra. 


\section{PUBLISHER}

Universidade Federal de Santa Catarina. Programa de Pós-Graduação em História. Portal de Periódicos UFSC. As ideias expressadas neste artigo são de responsabilidade de seus autores, não representando, necessariamente, a opinião dos editores ou da universidade.

\section{EDITORES}

Flávia Florentino Varella (Editora-chefe)

Tiago Kramer de Oliveira

Waldomiro Lourenço da Silva Júnior

\section{HISTÓRICO}

Recebido em: 18 de abril de 2019

Aprovado em: 13 de novembro de 2019

Como citar: PEGUIM, Cássia Natanie. Estado, desenvolvimento sustentável e governança no Brasil: políticas públicas para energia e água pós Rio-92. Esboços, Florianópolis, v. 27, n. 44, p. 78-93, jan./ abr. 2020 